\title{
Difference Between Left-Sided and Right-Sided Colorectal Cancer: A Focused Review of Literature
}

\author{
Burcin Baran ${ }^{\mathrm{a}, \mathrm{e}}$, Nazli Mert Ozupek ${ }^{\mathrm{a}}$, Nihal Yerli Tetik ${ }^{\mathrm{a}}$, Emine Acar ${ }^{\mathrm{b}, \mathrm{c}}$, \\ Omer Bekcioglua ${ }^{\text {a }}$ Yasemin Baskina, d, e
}

\begin{abstract}
Colorectal cancer is the third most common cancer worldwide with a high mortality rate at the advanced stages. However, colorectal cancer is not a single type of tumor; its pathogenesis depends on the anatomical location of the tumor and differs between right side and left side of the colon. Tumors in the proximal colon (right side) and distal colon (left side) exhibit different molecular characteristics and histology. In the right-sided tumors, mutations in the DNA mismatch repair pathway are commonly observed; and these tumors generally have a flat histology. In the left-sided tumors, chromosomal instability pathway-related mutations, such as $K R A S, A P C, P I K 3 C A$, p53 mutations are observed and these tumors demonstrate polypoid-like morphology. Therapy responses are totally different between these tumor entities. Left-sided colorectal cancer (LCRC) patients benefit more from adjuvant chemotherapies such as 5-fluorouracil (5-FU)-based regimes, and targeted therapies such as anti- epidermal growth factor receptor (EGFR) therapy, and have a better prognosis. Right-sided colorectal cancer (RCRC) patients do not respond well to conventional chemotherapies, but demonstrate more promising results with immunotherapies because these tumors have high antigenic load. For the development of effective therapy regimes and better treatment options, it is essential to evaluate right-sided and left-sided tumors as separate entities, and design the therapy regime considering the differences between these tumors.
\end{abstract}

Keywords: Colorectal cancer; Right side; Left side; Epidemiology; Molecular mechanism; Adjuvant chemotherapies; Targeted therapies; Immunotherapies

Manuscript submitted June 25, 2018, accepted July 18, 2018

aDepartment of Basic Oncology, Institute of Oncology, Dokuz Eylul University, Izmir, Turkey

bepartment of Translational Oncology, Dokuz Eylul University, Izmir, Turkey

'Department of Nuclear Medicine, Katip Celebi University, Izmir, Turkey

${ }^{\mathrm{d} D o k u z}$ Eylul University, Personalized Medicine and Pharmacogenomic Research Center, Izmir, Turkey

${ }^{\mathrm{e}}$ Corresponding Authors: Burcin Baran, Department of Basic Oncology, Institute of Oncology, Dokuz Eylul University, Balcova- Izmir, 35340, Turkey. Email: burcinbrn@gmail.com; Yasemin Baskin, Department of Basic Oncology, Institute of Oncology, Dokuz Eylul University, Balcova- Izmir, 35340, Turkey. Email: yasemin.baskin@deu.edu.tr

doi: https://doi.org/10.14740/gr1062w

\section{Introduction}

According to World Health Organization, colorectal cancer (CRC) is the third most common cancer in the world. In 2012, about 1.3 million people (746,000 men, 614,000 women) were diagnosed with CRC. Most of the CRC cases occurred in the developed regions of the world; the highest mortality rates were observed in Central and Eastern Europe, which was 20 per 100,000 men and 12 per 100,000 women [1]. The stage of the disease and presence of metastasis highly affects the survival rates among the patient group. While the 5-year survival rate is $90 \%$ for early-stage patients with localized disease, it is $70 \%$ for intermediate (regional invasive tumors) and $10 \%$ for advanced-stage patients with distant metastasis. Several factors including age, diet, hereditary polyposis syndrome and inflammatory bowel disease are associated with the development of CRC $[2,3]$.

Colorectal cancer originates from the epithelial tissue of the colon, and it may develop either on the right side or left side of the colon. Depending on the position, CRCs behave differently in terms of disease progression and overall survival. The difference between these tumors can be attributed to anatomical and developmental origin, or distinct carcinogenic factors (such as difference in bacterial population on the two sides of the colon, or exposure to distinct nutrients and bile acids), or a combination of both [4].

In the present review, we aimed to compare right-sided and left-sided colorectal tumors in terms of anatomical, histological, epidemiological, molecular, and genetic perspectives, and discuss the response of these tumors to adjuvant targeted therapy and immunotherapy (Table 1 [5-20]).

\section{Anatomical and Histological Perspective}

The colon is approximately $150 \mathrm{~cm}$ in length, and extends from the ileocecal valve up to the anus. It is composed of seven parts including cecum, ascending colon, transverse colon, descending colon, sigmoid colon, rectum, and anus [21]. This distinction between right-sided and left-sided colon is based on their embryological origins. The cecum, appendix, ascending colon, hepatic flexure, and proximal two thirds of the transverse colon have originated from the midgut, whereas distal one third of the transverse colon, splenic flexure, sigmoid colon, descending colon and rectum have originated from the hindgut. Hence, 
Table 1. Difference Between Right Sided and Left Sided Colorectal Tumor [5-20]

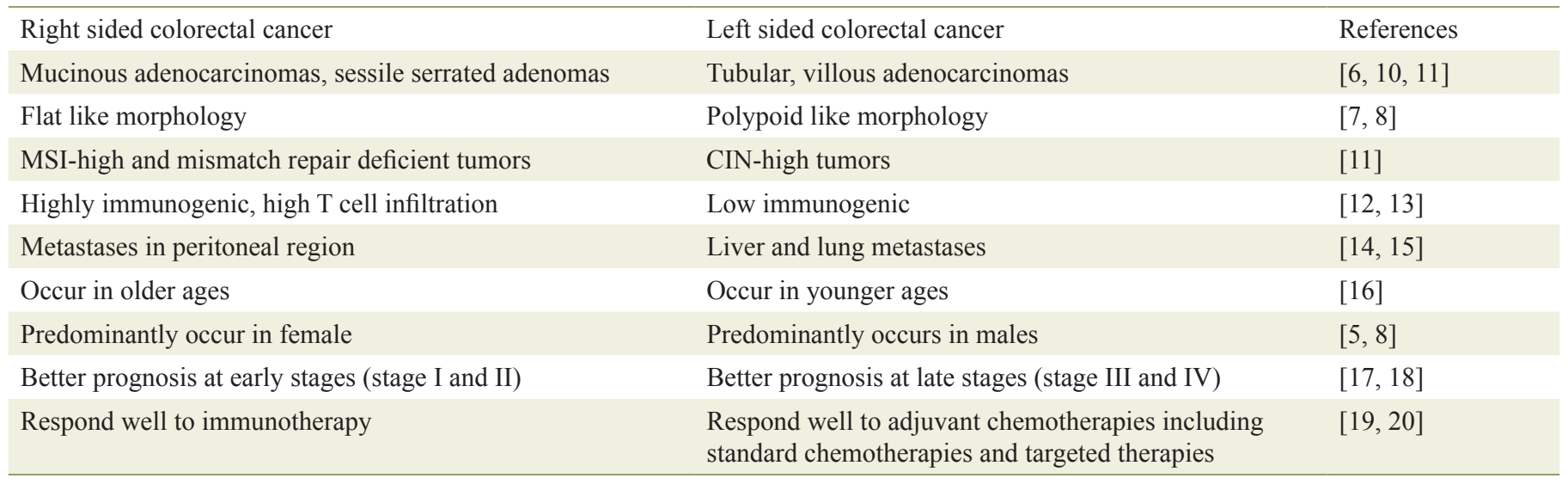

the right-sided $\mathrm{CRC}(\mathrm{RCRC})$ tumors arise from ascending colon, and proximal two thirds of the transverse colon and the left-sided CRC (LCRC) tumors arise from the descending and sigmoid colon, and distal one third of the transverse colon [5, 22].

Besides the difference in their origin, these tumors exhibit different histology. While right-sided tumors show sessile serrated adenomas or mucinous adenocarcinomas, left-sided tumors show tubular, villous and typical adenocarcinomas [6]. Since left-sided tumors have polypoid morphology, it is easier to detect them with colonoscopy in the early stages of carcinogenesis. Right-sided CRC have flat morphology that is difficult to detect $[7,8]$.

Right-sided CRC patients tend to have advanced and bigger tumors, which are often poorly differentiated. The genomic make-up of RCRC and LCRC are totally different from each other. While RCRC patients tend to have more microsatellite instability-high (MSI-high) tumors, LCRC patients tend to have chromosomal instability-high (CIN-high) tumors [4, 9].

Microsatellite instability-high tumors are characterized by the mutations or inactivation of the DNA mismatch repair system, and consequently single nucleotide mutations and alterations in the length of repetitive microsatellite sequences in the genome are observed in these tumors [23]. Sessile serrated adenomas (SSA) are premalignant lesions with abnormal proliferation, crypt distortion, and dilation. Sessile serrated adenomas can be distinguished from the traditional serrated adenomas due to the lack of cytological dysplasia in their early stage. They are frequently observed in RCRC and MSI-high tumors [10]. Mucinous adenocarcinomas, another type of $\mathrm{CRC}$, are commonly observed in RCRC and MSI-high tumors. Mucinous adenocarcinomas are characterized by excessive mucin excretion. Mucinous cancers have faster progression when compared with adenomatous polyps, and are commonly diagnosed in inflammatory bowel disease patients [11].

Furthermore, MSI-high tumors have more T cell infiltrates because these tumors carry more immunogenic mutations and harbor increased number of neoantigens. Histologically, many MSI-high tumors have shown Crohn's-like lymphoid reaction in the invasive front of the tumor. Presence of T cells in these tumors is associated with better prognosis and less frequent metastasis $[12,13,24]$.

Approximately $70-85 \%$ of CRCs develop via the traditional pathway, which is also known as CIN pathway. Chromosomal instability is characterized by widespread imbalances in chromosome number (aneuploidy) and loss of heterozygosity (LOH) [25]. In this classical model, the early lesions detected are tubular or villous or tubulovillous adenomas. Most of the adenomas in the CIN pathway are adenomatous polyps, but only $<5 \%$ harbor malignancy potential. However, villous adenomas, comprising only $5-10 \%$ of polyps have a high potential (35-40\%) of malignancy [26]. The presence of villous polyps in the patient is the determining factor for the risk of malignancy in patients [26]. These polyps turn into carcinomas in 10 to 20 years owing to the accumulation of sequential mutations. Hence, it is essential to excise these polyps by polypectomy in the early stages to reduce the risk of CRC [27].

Metastasis of CRC significantly affects the overall survival among the patients. Distant metastases are present in approximately $25 \%$ of patients; diagnosis and resectability of metastasis significantly dictates the outcome [14]. The sites of metastasis differ between LCRC and RCRC patients. While LCRC patients tend to have liver and lung metastasis, RCRC patients have peritoneal carcinomatosis [15]. Historically peritoneal metastases had the worst outcome; however, with the advance in hyperthermic intraperitoneal chemotherapy (HIPEC), the survival rates have improved among this patient group [28].

\section{Epidemiological Perspective}

People aged 50 or above have an increased risk of developing CRC. More than $90 \%$ of people diagnosed with CRC are over 50 years of age; however, CRC incidence among the younger people is likely to increase in recent years [16]. The overall survival of the patients is dependent on the stage of cancer, and the presence of metastasis. However, most of the studies have shown that the prognosis of RCRC is worse than that of LCRC [29-31]. In a cohort study based on the data from Surveillance, Epidemiology, and End Results Program (SEER) in USA, the median survival of the patients was found to be 78 
months for RCRC, and 89 months for LCRC $(\mathrm{P}=0.001)$ [17]. In another study, the 5-year survival rate was found to be $73 \%$ for RCRC and 74\% for LCRC among 17,000 patients [15]. Interestingly, comparison between stage III and IV RCRC and LCRC patients exhibited a poor overall survival of RCRC patients, while stage I and II RCRC patients exhibited a better overall survival than LCRC patients [17]. The same results were obtained in another study carried out with a Japanese patient cohort. The prognosis of stage I and II tumors in the patients with RCRC was significantly better than in patients with LCRC. However, prognosis of the advanced stages (stages III and IV) in the Japanese patients with RCRC was worse, and the recurrence rates after resection were higher compared to the patients with LCRC [18]. Interestingly, no survival benefit was observed for adjuvant chemotherapies in the left-sided and right-sided CRC patients who had undergone surgical resection at an early stage (stage I and stage II); but it was shown to improve the survival rates in stage III and stage IV LCRC and RCRC patients [32]. There is still an ongoing debate on whether stage II patients should receive chemotherapy or not. While assays such as Oncotype DX or ColoPrint can predict the recurrence rates among stage II patients, they still have a limited role in predicting the therapy responses among these patients [33]. Hence, there is a need for the development of new biomarkers for the prediction of therapy responses. Immunoscore is one of the new markers, which may be helpful for the prediction of immunotherapy responses [34].

Furthermore, the presence of metastases and their status (resectable or non-resectable) are the factors affecting the overall survival among the patients. In the study by Sasaki et al, the overall survival was 47.4 months for RCRC patients with liver metastasis versus 63.0 months for LCRC patients with liver metastasis. The recurrence of tumor, following resection was observed earlier (24.8 months) in RCRC patients than in LCRC patients (35.9 months) ( $\mathrm{P}=0.01)$ [35]. Furthermore, meta-analysis by Holch et al showed that metastatic RCRC patients had significantly worse prognosis than metastatic LCRC patients [36].

According to different cohort studies, RCRC occurs predominantly in females and older people, and LCRC occurs predominantly in males, and at an early age $[5,8]$. However, it should be noted that LCRC also occurs after 50 years of age, with a frequency more than that of RCRC [37].

The aforementioned survival rates and epidemiological data are for sporadic CRC patients. There are hereditary cases as well. Hereditary cancer syndromes except familial adenomatous polyposis (FAP) tend to occur in the right side of the colon. Hereditary non polyposis colorectal cancer (HNPCC) or Lynch syndrome is the most common form of hereditary CRC, observed in 1-6\% of all CRC cases. The patients with HNPCC have an $80 \%$ risk of developing CRC; the mean age of $\mathrm{HN}$ PCC is 44 years, which is approximately 20 years earlier than $\mathrm{CRC}$ cases. Familial adenomatous polyposis is a syndrome caused because of inherited mutation in one allele of adenomatous polyposis coli $(A P C)$ gene. The mean age for the onset of the disease is 16 years, but can occur early at 8 years of age. The number and size of polyps increase with time. Most of the CRC (about 70\%) tend to occur in the left side, whereas, a small percentage (about 10\%) occurs in the right side [38,39].

\section{Molecular Biology and Genetic Perspective}

Colorectal cancer is a heterogeneous disease, exhibiting a variety of genetic and epigenetic alterations [40]. At least two molecular pathways have been described for CRC. In the MSI pathway, hypermutated cancers with high microsatellite instability, due to mutations in DNA mismatch repair system or in DNA proofreading mechanism, are observed. In the CIN pathway, high frequency of DNA copy number alterations, and non-hypermutated tumors are observed [40, 41]. A third mechanism, $\mathrm{CpG}$ island methylator phenotype (CIMP) is related to aberrant methylation in several genes, and is commonly observed in sporadic cases with DNA mismatch repair pathway deficient (dMMR) and MSI-high tumors. BRAF mutations are also commonly observed with CIMP phenotype $[42,43]$.

Table 2 shows the list of mutated genes in CIN- and MSIhigh tumors. While RCRC tumors tend to be MSI-high, LCRC tumors are CIN-high tumors [27, 44-46].

\section{CIN pathway}

Left-sided CRC predominantly follow the CIN molecular pathway. Fearon and Vogelstein first proposed the multi-step genetic model for colorectal carcinogenesis, which is known as traditional pathway (CIN pathway). In this model, carcinogenesis begins with the inactivation or deletion of adenomatous polyposis coli $(A P C)$ tumor suppressor gene, followed by the activation of Kirsten ras homolog $(K R A S)$ oncogene, the inactivation of $p 53$ tumor suppressor gene and other mutations [47, 48]. Multi-institutional The Cancer Genome Atlas (TCGA) study also confirmed the model and proposed various mutations. According to TCGA study, APC, TP53, KRAS, PIK3CA, FBXW7, SMAD4, TCF7L2, and NRAS are the most frequently mutated genes in CIN tumors. APC deletion and Wnt pathway activation, as well as RAS pathway activation and TP53 pathway inactivation have been observed in many tumors $[25,44]$. Aurora kinases and Polo-like kinases (Plks) are proteins that are responsible for centromere assembly, duplication, mitotic spindle formation, and mitotic entry. Dysregulated expression of Aurora and Polo kinases can lead to CIN phenotype. For example, dysregulated expression of Aurora B and PLK highly correlated with CIN phenotype and advanced stages of CRC [49-51].

KRAS mutations are commonly observed in LCRC cases having a CIN phenotype. KRAS mutations are commonly observed in Codon 12 and 13, resulting in constitutively active RAS protein, which in turn activates the downstream pathways leading to cell proliferation and cell survival [52]. KRAS mutations are found in $35-45 \%$ of CRC cases [53]. Whether KRAS can be a prognostic factor for CRC is still debatable. Most studies have claimed that the effect of KRAS on prognosis is based on the mutation type and location. While $K R A S$ codon 12 mutations are proposed to be associated with the increment in CRC-induced mortality, codon 13 mutations are not associated with survival [54]. In the RASCAL study, especially guanine $(\mathrm{G})$ to thymidine $(\mathrm{T})$ conversion in the KRAS codon 
Table 2. List of Mutated Genes in CIN- and MSI-High Tumors [27, 44-46]

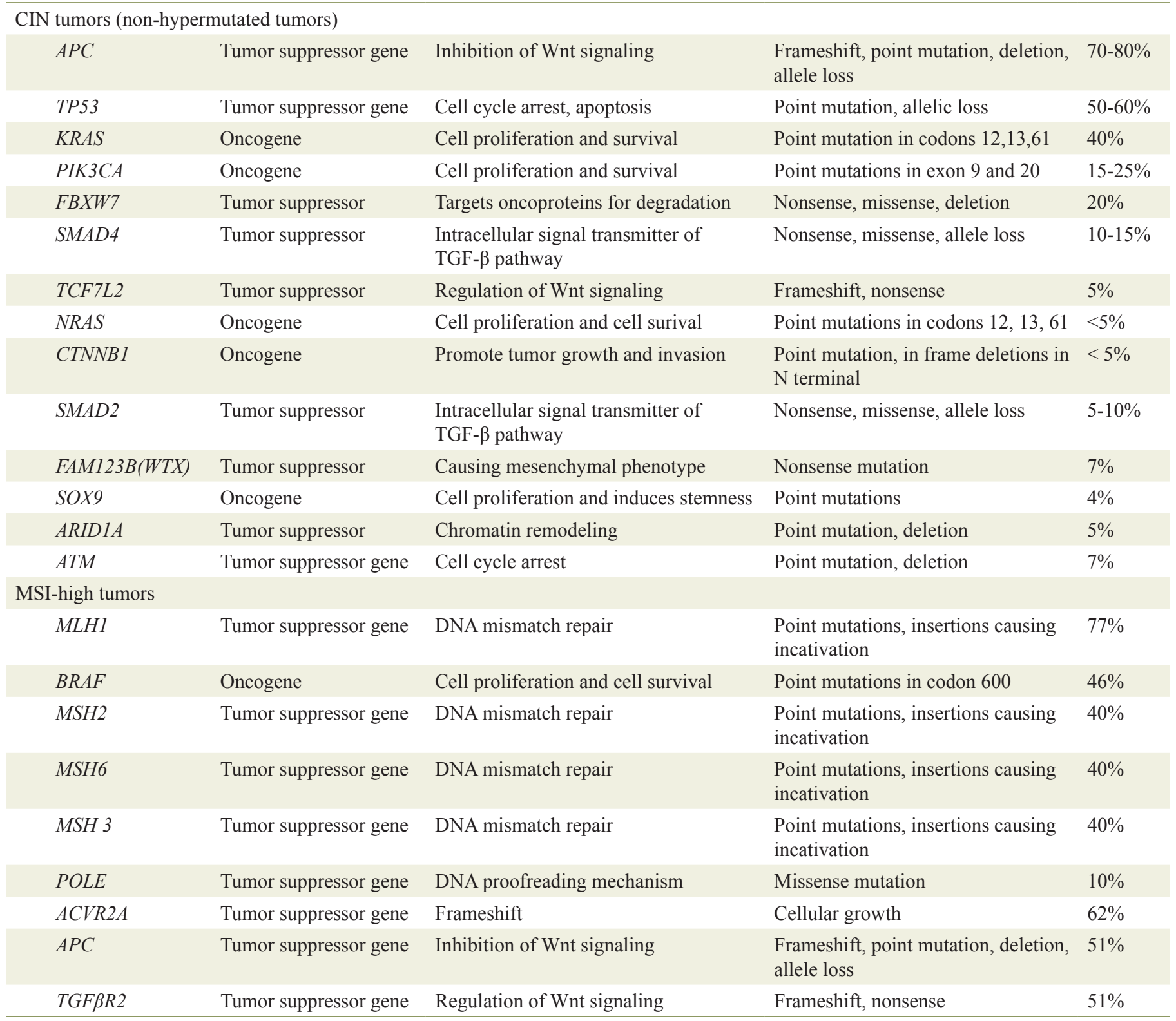

was shown to be associated with higher mortality [55]. In the RASCAL II study, the glycine to valine mutation was shown to have an effect on overall survival rates of CRC patients [56]. However, in PETACC3 study, they did not find any association between KRAS mutations and overall survival [57]. KRAS mutational status among the CRC patients is an important predictive factor for anti- epidermal growth factor receptor (EGFR) therapy, and not as a prognostic factor [58].

\section{MSI pathway}

Right-sided CRC predominantly characterized by microsatellite instability, and are hypermutated tumors. Deficient mismatch repair/microsatellite instability-high (dMMR/MSIhigh) are caused by defects in the DNA mismatch repair system, which further accelerates the accumulation of single nucleotide mutations, and alterations in the length of repetitive microsatellite sequences in the genome. Most HNPCC tumors, and a portion of non-hereditary CRCs showed high dMMR/ MSI status [23, 59].

Mismatch repair genes $M S H 2, M L H 1$, MSH6, PMS2, MLH3 and Exo2 have been linked with HNPCC in the linkage studies carried out with the families of the affected patients [59]. Furthermore, hypermethylation of the MLH1 gene promoter was observed in sporadic MSI-high CRC. Interestingly, $B R A F$ V600E mutations were commonly observed with MLH1 mutations in sporadic cases and with CIMP [60, 61]. DNA 
polymerase epsilon (POLE) mutations have been observed in a small subset of microsatellite-stable and hypermutated CRCs that affects the proofreading activity of the enzyme, leading to the misincorporation of the bases during DNA replication [62]. According to the TCGA study, $A C V R 2 A, A P C$, TGFB-R2, MSH3, MSH6, SLC9A9, TCF7L2, and BRAFV600E are the most frequently mutated genes in these hypermutated tumors [44]. The TGF- $\beta$ pathway was found to be inactivated in dMMR/MSI-high tumors in the study. It is one of the essential pathways in colorectal carcinogenesis, which has dual functions based on canonical and non-canonical pathways. Although it has a growth-suppressive function in the initial stages of tumorigenesis, it contributes to metastasis in the advanced stages [63]. In the canonical pathway, TGF- $\beta$ interacts with the SMAD transcriptional factor family members SMAD2 and SMAD3 and phosphorylates them, which in turn activates SMAD4. Later, SMAD complexes translocate into the nucleus; and either induce or repress the expression of several genes [64]. SMAD4 leads to apoptosis and cell cycle suppression in epithelial cells [65]. The ACVR2A mutation occurs commonly with $T G F-\beta$ mutations and is thought to play a role in tumor suppression as well [66].

The anti-apoptotic role of TGF- $\beta$ is exerted via the noncanonical pathway, independently of SMAD proteins. Activin is one of the essential components of TGF- $\beta$ pathway, which induces a pro-metastatic phenotype in colorectal cancer cells [67]. Activin also down-regulates p21, which is a cyclindependent kinase inhibitor and mediates p53-dependent cell cycle arrest, hence leading to more proliferative and invasive phenotype in colorectal cancer cells [68].

\section{Molecular Targeted Therapies}

Systemic chemotherapy for CRC includes mainly fluoropyrimidines (5-fluorouracil (5-FU) and oral capecitabine), irinotecan, and oxaliplatin [69]. Fluorouracil is a fluorinated pyrimidine that acts primarily by inhibiting the thymidylate synthetase enzyme; commonly administered with leucovorin, which is thought to stabilize the interaction of fluorouracil with this enzyme [70]. Among the metastatic CRC patients administered with fluorouracil and leucovorin, $20 \%$ had reduction in tumor size and showed an increment in overall survival from 6 months to 12 months [71, 72]. However, it should be emphasized that these adjuvant chemotherapies are mostly effective in the advanced stage (stage III and IV) patients after resection of tumors [73]. Furthermore, these adjuvant chemotherapies have shown to be more effective among patients with microsatellite-stable tumors or tumors with low frequency of microsatellite instability, hence LCRC patients have benefited more from standard chemotherapies [19].

Targeted therapeutics, especially for metastatic advanced CRC cases, have been developed and used in combination with conventional chemotherapy that has improved the overall survival among the patients. While some of these agents (bevacizumab, aflibercept, ramucirumab, and regorafenib) specifically target angiogenic pathways, others (cetuximab and panitumumab) target the EGFR pathway [74]. In conventional therapy and/or targeted therapy settings, LCRC tumors have better outcomes than RCRC tumors. According to the CALGB/SWOG 80405 study, among the patients who received cetuximab, median overall survival was 36 months for patients with left-sided tumors and 16.7 months for patients with rightsided tumors $(\mathrm{HR}=1.87,95 \% \mathrm{CI}=1.48-2.32, \mathrm{P}<0.0001)$ [75]. Furthermore, in the Canadian NCIC CO.17 trial, LCRC patients benefited more from cetuximab therapy than RCRC patients [76]. The same results were obtained with CRYSTAL and FIRE trials as well [77]. In the PRIME study, addition of panitumumab to FOLFOX increased the overall survival among LCRC patients, whereas it was not effective in RCRC patients (for LCRC, 32.5 months versus 23.6 months, adjusted $\mathrm{HR}=0.68, \mathrm{P}=0.0027$; for RCRC 22.5 versus 21.5 months, adjusted HR $=0.97, \mathrm{P}=0.9295$ ) [78]. Anti-EGFR therapies improved the overall survival in patients with left-sided $K R A S$ wild type tumors, but not in patients with right-sided wild type tumors [79].

Bevacizumab is another commonly used agent for CRC that targets the vascular endothelial growth factor receptor (VEGFR). Following bevacizumab treatment, while median overall survival was 31.4 months for patients with left-sided tumors, it was 24.2 months for patients with right-sided tumors $(\mathrm{HR}=1.32,95 \% \mathrm{CI}=1.05-1.65, \mathrm{P}=0.01)$. In the CALGB/ SWOG 80405 study, patients with right-sided tumors benefited more from bevacizumab treatment than cetuximab treatment [75]. While the combination of bevacizumab and systemic chemotherapy reduced the mortality in both RCRC and LCRC patients, the combination of cetuximab and systemic chemotherapy was shown to be effective only in LCRC patients [80].

Furthermore, meta-analysis of clinical trials has shown that LCRC patients with wild type KRAS had significantly greater survival benefit from anti-EGFR treatment regimes compared to anti-VEGFR therapies when combined with standard chemotherapies $(\mathrm{HR}=0.71 ; 95 \% \mathrm{CI}=0.58-0.85$; $\mathrm{P}=0.0003)[36]$.

\section{Immunotherapies}

MSI-high tumors are located predominantly in the right side of the colon. These tumors have highly activated lymphocytic microenvironment, and present a high degree of neoantigens [81]. Despite the active immunogenic load, these tumor cells cannot be eliminated by the immune system. $\mathrm{T}$ cells are induced by antigen recognition, as a result $\mathrm{T}$ cell regulation is highly dependent on co-stimulatory and inhibitory signals. Immune checkpoint regulators, such as programmed death protein 1 (PD-1), programmed death receptor ligand 1 (PDL1), and T lymphocyte-associated antigen 4 (CTLA-4) repress $\mathrm{T}$ cell activation. In normal conditions, immune checkpoint regulators are essential for autoimmunity, however tumor cells highly use these regulators as an anti-tumor immune response $[82,83]$.

Immune checkpoint inhibitors are antagonists, functioning by repressing inhibitory PD-1, PD-L1 and CTLA-4 receptor activities [84]. However, it should be emphasized that CTLA4 and PD-1/PD-L1 act in completely different mechanisms; 
CTLA-4 predominantly functions in the initial steps of immune activation, functioning in CD4 $+\mathrm{T}$ cells (regulator and effector $\mathrm{T}$ cells) for $\mathrm{T}$ cell priming and activation, whereas PD-L1 is either expressed by macrophages or tumors cells and interacts with CD8+ T cells [85].

Interestingly, tumor infiltrating lymphocytes express high level of PD-L1, which is thought to be a result of chronic stimulation because of the neoantigen load [86]. Tumors with high antigenic load seem to benefit more from immunotherapies. Metastatic melanoma is one of the tumors with high immunogenic load and melanoma patients are highly benefiting from anti-CTLA-4 and anti-PD-1 therapies [87, 88].

Ipilimumab and tremelimumab are currently used as antiCTLA-4 inhibitors. However, anti-CTLA-4 inhibitors did not show any significant benefit in CRC patients [89]. Anti-PD-1 and anti-PD-L1 inhibitors seem to have more promising results in CRC patients. Anti-PD-1 inhibitor pembrolizumab has been shown to be effective in MSI-high CRC tumors, however it is non-effective in MSI-stable CRC tumors [90]. The efficiency of pembrolizumab was evaluated with multi-centered KEYNOTE study that showed promising results in MSI-high tumors [91, 92]. Furthermore, the effectiveness of nivolumab, which is an anti-PD-1 antibody, had been studied in a large cohort of CRC patients in Checkmate 142 trial. Nivolumab has shown promising results in MSI-high tumors [93]. The combination of two immunotherapies, nivolumab and ipilimumab was also assessed among the CRC population that showed improved survival benefit, and was found to be well-tolerated by patients [94]. Overall, immunotherapies are a promising therapeutic option for patients with MSI-high tumors that were resistant to fluoropyrimidine, irinotecan, and oxaliplatin regimes, or have unresectable and metastatic MSI-high tumors [20].

\section{Conclusions}

Colorectal cancer is the third most common cancer with high mortality rates in the advanced stages. Although the detection of CRC in the early stages is possible with routine colonoscopy screening, the prevalence is still increasing, especially in developing countries $[95,96]$. Notably, CRC is not one type of disease, rather it acts as two different diseases in the same organ. The behavior of CRC is highly affected by the anatomical location of the tumor, which in turn affects its molecular and immunological characteristics. Understanding the characteristics of these two different entities is very important for developing effective therapies [21,97].

Right-sided CRC tumors are commonly microsatellite instable tumors, whereas, LCRC tumors are chromosomal instable tumors. As discussed in the first part of the review, RCRC and LCRC tumors exhibit different histological and molecular characteristics. It is easier to detect LCRC tumors as small adenomas at an early stage with colonoscopy screening. Right-sided CRC tumors are still detectable at an early stage, but with much more difficult than LCRC tumors because of their flat morphology [98, 99]. Thus, RCRC tumors are commonly detected in more advanced stages than LCRC tumors.
Although surgical resection is the primary option for all stages and adjuvant therapies seem to be effective in improving the survival among the patients $[32,100,101]$, there is still a need for more effective therapies for both RCRC and LCRC stage IV patients. In this setting, two new therapy options, namely, targeted therapies and immunotherapies, can be recommended as monotherapies or in combination with adjuvant therapies. According to many phase II studies, patients with $K R A S$ wild type LCRC tumors benefit well from targeted therapies including anti-EGFR or anti-VEGFR therapies, whereas, patients with MSI-high RCRC tumors appear to benefit more from immunotherapies $[102,103]$.

\section{References}

1. Ferlay J, Soerjomataram I, Dikshit R, Eser S, Mathers C, Rebelo M, Parkin DM, et al. Cancer incidence and mortality worldwide: sources, methods and major patterns in GLOBOCAN 2012. Int J Cancer. 2015;136(5):E359-386.

2. Thelin C, Sikka S. Epidemiology of colorectal cancer - incidence, lifetime risk factors statistics and temporal trends. In: Ettarh R(ed). Screening for Colorectal Cancer with Colonoscopy. Intech Open. 2015;1-18.

3. Brenner H, Kloor M, Pox CP. Colorectal cancer. Lancet. 2014;383(9927):1490-1502.

4. Glebov OK, Rodriguez LM, Nakahara K, Jenkins J, Cliatt J, Humbyrd CJ, DeNobile J, et al. Distinguishing right from left colon by the pattern of gene expression. Cancer Epidemiol Biomarkers Prev. 2003;12(8):755-762.

5. Iacopetta B. Are there two sides to colorectal cancer? Int J Cancer. 2002;101(5):403-408.

6. Marzouk O, Schofield J. Review of histopathological and molecular prognostic features in colorectal cancer. Cancers (Basel). 2011;3(2):2767-2810.

7. Gualco G, Reissenweber N, Cliche I, Bacchi CE. Flat elevated lesions of the colon and rectum: a spectrum of neoplastic and nonneoplastic entities. Ann Diagn Pathol. 2006;10(6):333-338.

8. Nawa T, Kato J, Kawamoto H, Okada H, Yamamoto H, Kohno H, Endo H, et al. Differences between right- and left-sided colon cancer in patient characteristics, cancer morphology and histology. J Gastroenterol Hepatol. 2008;23(3):418-423.

9. Carethers JM. One colon lumen but two organs. Gastroenterology. 2011;141(2):411-412.

10. Bordacahar B, Barret M, Terris B, Dhooge M, Dreanic J, Prat F, Coriat R, et al. Sessile serrated adenoma: from identification to resection. Dig Liver Dis. 2015;47(2):95102.

11. Hugen N, Brown G, Glynne-Jones R, de Wilt JH, Nagtegaal ID. Advances in the care of patients with mucinous colorectal cancer. Nat Rev Clin Oncol. 2016;13(6):361-369.

12. Galon J, Costes A, Sanchez-Cabo F, Kirilovsky A, Mlecnik B, Lagorce-Pages C, Tosolini M, et al. Type, density, and location of immune cells within human colorectal tumors predict clinical outcome. Science. 2006;313(5795):19601964.

13. Ogino S, Nosho K, Irahara N, Meyerhardt JA, Baba Y, 
Shima K, Glickman JN, et al. Lymphocytic reaction to colorectal cancer is associated with longer survival, independent of lymph node count, microsatellite instability, and $\mathrm{CpG}$ island methylator phenotype. Clin Cancer Res. 2009;15(20):6412-6420.

14. Vatandoust S, Price TJ, Karapetis CS. Colorectal cancer: Metastases to a single organ. World J Gastroenterol. 2015;21(41):11767-11776.

15. Benedix F, Kube R, Meyer F, Schmidt U, Gastinger I, Lippert H, Colon/Rectum Carcinomas Study G. Comparison of 17,641 patients with right- and left-sided colon cancer: differences in epidemiology, perioperative course, histology, and survival. Dis Colon Rectum. 2010;53(1):57-64.

16. Haggar FA, Boushey RP. Colorectal cancer epidemiology: incidence, mortality, survival, and risk factors. Clin Colon Rectal Surg. 2009;22(4):191-197.

17. Meguid RA, Slidell MB, Wolfgang CL, Chang DC, Ahuja N. Is there a difference in survival between right- versus left-sided colon cancers? Ann Surg Oncol. 2008;15(9):2388-2394.

18. Moritani K, Hasegawa H, Okabayashi K, Ishii Y, Endo T, Kitagawa Y. Difference in the recurrence rate between right- and left-sided colon cancer: a 17-year experience at a single institution. Surg Today. 2014;44(9):1685-1691.

19. Ribic CM, Sargent DJ, Moore MJ, Thibodeau SN, French AJ, Goldberg RM, Hamilton SR, et al. Tumor microsatellite-instability status as a predictor of benefit from fluorouracil-based adjuvant chemotherapy for colon cancer. N Engl J Med. 2003;349(3):247-257.

20. Passardi A, Canale M, Valgiusti M, Ulivi P. Immune checkpoints as a target for colorectal cancer treatment. Int J Mol Sci. 2017;18(6):1324.

21. Gervaz P, Bucher P, Morel P. Two colons-two cancers: paradigm shift and clinical implications. J Surg Oncol. 2004;88(4):261-266.

22. Mik M, Berut M, Dziki L, Trzcinski R, Dziki A. Rightand left-sided colon cancer - clinical and pathological differences of the disease entity in one organ. Arch Med Sci. 2017;13(1):157-162.

23. Boland CR, Thibodeau SN, Hamilton SR, Sidransky D, Eshleman JR, Burt RW, Meltzer SJ, et al. A National Cancer Institute Workshop on Microsatellite Instability for cancer detection and familial predisposition: development of international criteria for the determination of microsatellite instability in colorectal cancer. Cancer Res. 1998;58(22):5248-5257.

24. Giannakis M, Mu XJ, Shukla SA, Qian ZR, Cohen O, Nishihara R, Bahl S, et al. Genomic Correlates of Immune-Cell Infiltrates in Colorectal Carcinoma. Cell Rep. 2016;17(4):1206.

25. Pino MS, Chung DC. The chromosomal instability pathway in colon cancer. Gastroenterology. 2010;138(6):20592072.

26. Amersi F, Agustin M, Ko CY. Colorectal cancer: epidemiology, risk factors, and health services. Clin Colon Rectal Surg. 2005;18(3):133-140.

27. Roper J, Huang KE. Molecular mechanisms of colorectal carcinogenesis. In: Haigis KM (ed). Molecular Pathogenesis of Colorectal Cancer, Springer Science \& Business
Media New York. 2013;1-42.

28. Verwaal VJ, Bruin S, Boot H, van Slooten G, van Tinteren H. 8-year follow-up of randomized trial: cytoreduction and hyperthermic intraperitoneal chemotherapy versus systemic chemotherapy in patients with peritoneal carcinomatosis of colorectal cancer. Ann Surg Oncol. 2008;15(9):2426-2432.

29. Petrelli F, Tomasello G, Borgonovo K, Ghidini M, Turati L, Dallera $\mathrm{P}$, Passalacqua $\mathrm{R}$, et al. Prognostic survival associated with left-sided vs right-sided colon cancer: a systematic review and meta-analysis. JAMA Oncol. 2017;3(2):211-219.

30. Loupakis F, Yang D, Yau L, Feng S, Cremolini C, Zhang W, Maus MK, et al. Primary tumor location as a prognostic factor in metastatic colorectal cancer. J Natl Cancer Inst. 2015;107(3):dju427.

31. Boisen MK, Johansen JS, Dehlendorff C, Larsen JS, Osterlind K, Hansen J, Nielsen SE, et al. Primary tumor location and bevacizumab effectiveness in patients with metastatic colorectal cancer. Ann Oncol. 2013;24(10):2554-2559.

32. Weiss JM, Schumacher J, Allen GO, Neuman H, Lange EO, Loconte NK, Greenberg CC, et al. Adjuvant chemotherapy for stage II right-sided and left-sided colon cancer: analysis of SEER-medicare data. Ann Surg Oncol. 2014;21(6):1781-1791.

33. Lee JJ, Chu E. Adjuvant chemotherapy for stage II colon cancer: The Debate Goes On. J Oncol Pract. 2017;13(4):245-246.

34. Bibeau F. Galon J, Mlecnik B, Marliot F, et al (2016) Validation of the immunoscore (IM) as a prognostic marker in stage I/II/III colon cancer: results of a worldwide consortium-based analysis of 1,336 patients. J Clin Oncol 34(suppl):abstr 3500. Colon \& Rectum. 2016;10(3):197199.

35. Sasaki K, Andreatos N, Margonis GA, He J, Weiss M, Johnston F, Wolfgang C, et al. The prognostic implications of primary colorectal tumor location on recurrence and overall survival in patients undergoing resection for colorectal liver metastasis. J Surg Oncol. 2016;114(7):803809.

36. Holch JW, Ricard I, Stintzing S, Modest DP, Heinemann $\mathrm{V}$. The relevance of primary tumor location in patients with metastatic colorectal cancer. Eur J Cancer. 2017;70:87-98.

37. Jess P, Hansen IO, Gamborg M, Jess T, Danish Colorectal Cancer G. A nationwide Danish cohort study challenging the categorisation into right-sided and left-sided colon cancer. BMJ Open. 2013;3(5):e002608.

38. Half E, Bercovich D, Rozen P. Familial adenomatous polyposis. Orphanet J Rare Dis. 2009;4:22.

39. Ellis CN. Colonic adenomatous polyposis syndromes: clinical management. Clin Colon Rectal Surg. 2008;21(4):256-262.

40. Galon J, Mlecnik B, Bindea G, Angell HK, Berger A, Lagorce C, Lugli A, et al. Towards the introduction of the 'Immunoscore' in the classification of malignant tumours. J Pathol. 2014;232(2):199-209.

41. Muller MF, Ibrahim AE, Arends MJ. Molecular patho- 
logical classification of colorectal cancer. Virchows Arch. 2016;469(2):125-134.

42. Kambara T, Simms LA, Whitehall VL, Spring KJ, Wynter $\mathrm{CV}$, Walsh MD, Barker MA, et al. BRAF mutation is associated with DNA methylation in serrated polyps and cancers of the colorectum. Gut. 2004;53(8):1137-1144.

43. Issa JP. CpG island methylator phenotype in cancer. Nat Rev Cancer. 2004;4(12):988-993.

44. Cancer Genome Atlas N. Comprehensive molecular characterization of human colon and rectal cancer. Nature. 2012;487(7407):330-337.

45. Fearon ER. Molecular genetics of colorectal cancer. Annu Rev Pathol. 2011;6:479-507.

46. Peltomaki P, Vasen H. Mutations associated with HNPCC predisposition - Update of ICG-HNPCC/INSiGHT mutation database. Dis Markers. 2004;20(4-5):269-276.

47. Fearon ER, Vogelstein B. A genetic model for colorectal tumorigenesis. Cell. 1990;61(5):759-767.

48. Vogelstein B, Fearon ER, Hamilton SR, Kern SE, Preisinger AC, Leppert $\mathrm{M}$, Nakamura $\mathrm{Y}$, et al. Genetic alterations during colorectal-tumor development. N Engl J Med. 1988;319(9):525-532.

49. Katayama H, Ota T, Jisaki F, Ueda Y, Tanaka T, Odashima S, Suzuki F, et al. Mitotic kinase expression and colorectal cancer progression. J Natl Cancer Inst. 1999;91(13):11601162.

50. Macurek L, Lindqvist A, Lim D, Lampson MA, Klompmaker R, Freire R, Clouin C, et al. Polo-like kinase-1 is activated by aurora $\mathrm{A}$ to promote checkpoint recovery. Nature. 2008;455(7209):119-123.

51. Takahashi T, Sano B, Nagata T, Kato H, Sugiyama Y, Kunieda K, Kimura M, et al. Polo-like kinase 1 (PLK1) is overexpressed in primary colorectal cancers. Cancer Sci. 2003;94(2):148-152.

52. Al-Mulla F, Milner-White EJ, Going JJ, Birnie GD. Structural differences between valine-12 and aspartate-12 Ras proteins may modify carcinoma aggression. J Pathol. 1999;187(4):433-438.

53. Tan C, Du X. KRAS mutation testing in metastatic colorectal cancer. World J Gastroenterol. 2012;18(37):51715180 .

54. Imamura Y, Morikawa T, Liao X, Lochhead P, Kuchiba A, Yamauchi M, Qian ZR, et al. Specific mutations in KRAS codons 12 and 13, and patient prognosis in 1075 BRAF wild-type colorectal cancers. Clin Cancer Res. 2012;18(17):4753-4763.

55. Andreyev HJ, Norman AR, Cunningham D, Oates JR, Clarke PA. Kirsten ras mutations in patients with colorectal cancer: the multicenter "RASCAL" study. J Natl Cancer Inst. 1998;90(9):675-684.

56. Andreyev HJ, Norman AR, Cunningham D, Oates J, Dix BR, Iacopetta BJ, Young J, et al. Kirsten ras mutations in patients with colorectal cancer: the 'RASCAL II' study. Br J Cancer. 2001;85(5):692-696.

57. Roth AD, Tejpar S, Delorenzi M, Yan P, Fiocca R, Klingbiel D, Dietrich D, et al. Prognostic role of KRAS and BRAF in stage II and III resected colon cancer: results of the translational study on the PETACC-3, EORTC 40993, SAKK 60-00 trial. J Clin Oncol. 2010;28(3):466-474.
58. Adelstein BA, Dobbins TA, Harris CA, Marschner IC, Ward RL. A systematic review and meta-analysis of KRAS status as the determinant of response to anti-EGFR antibodies and the impact of partner chemotherapy in metastatic colorectal cancer. Eur J Cancer. 2011;47(9):13431354.

59. Boland CR, Goel A. Microsatellite instability in colorectal cancer. Gastroenterology. 2010;138(6):2073-2087, e22073.

60. Domingo E, Laiho P, Ollikainen M, Pinto M, Wang L, French AJ, Westra J, et al. BRAF screening as a low-cost effective strategy for simplifying HNPCC genetic testing. J Med Genet. 2004;41(9):664-668.

61. Nazemalhosseini Mojarad E, Farahani RK, Haghighi MM, Aghdaei HA, Kuppen PJ, Zali MR. Clinical implications of BRAF mutation test in colorectal cancer. Gastroenterol Hepatol Bed Bench. 2013;6(1):6-13.

62. Guerra J, Pinto C, Pinto D, Pinheiro M, Silva R, Peixoto A, Rocha P, et al. POLE somatic mutations in advanced colorectal cancer. Cancer Med. 2017;6(12):2966-2971.

63. Principe DR, Doll JA, Bauer J, Jung B, Munshi HG, Bartholin L, Pasche B, et al. TGF-beta: duality of function between tumor prevention and carcinogenesis. J Natl Cancer Inst. 2014;106(2):djt369.

64. Massague J. TGFbeta in Cancer. Cell. 2008;134(2):215230.

65. Zhang B, Halder SK, Kashikar ND, Cho YJ, Datta A, Gorden DL, Datta PK. Antimetastatic role of Smad4 signaling in colorectal cancer. Gastroenterology. 2010;138(3):969980 e961-963.

66. Lee YJ, Hong KH, Yun J, Oh SP. Generation of activin receptor type IIB isoform-specific hypomorphic alleles. Genesis. 2006;44(10):487-494.

67. Staudacher JJ, Bauer J, Jana A, Tian J, Carroll T, Mancinelli G, Ozden $\mathrm{O}$, et al. Activin signaling is an essential component of the TGF-beta induced pro-metastatic phenotype in colorectal cancer. Sci Rep. 2017;7(1):5569.

68. Bauer J, Sporn JC, Cabral J, Gomez J, Jung B. Effects of activin and TGFbeta on p21 in colon cancer. PLoS One. 2012;7(6):e39381.

69. Ohhara Y, Fukuda N, Takeuchi S, Honma R, Shimizu Y, Kinoshita I, Dosaka-Akita H. Role of targeted therapy in metastatic colorectal cancer. World J Gastrointest Oncol. 2016;8(9):642-655.

70. Sobrero A, Guglielmi A, Grossi F, Puglisi F, Aschele C. Mechanism of action of fluoropyrimidines: relevance to the new developments in colorectal cancer chemotherapy. Semin Oncol. 2000;27(5 Suppl 10):72-77.

71. Thirion P, Michiels S, Pignon JP, Buyse M, Braud AC, Carlson RW, O'Connell M, et al. Modulation of fluorouracil by leucovorin in patients with advanced colorectal cancer: an updated meta-analysis. J Clin Oncol. 2004;22(18):3766-3775.

72. Wolpin BM, Majer RJ. Systematic treatment of colorectal cancer. Gastroenterol. 2008;134(5):1296-1310.

73. Moertel CG, Fleming TR, Macdonald JS, Haller DG, Laurie JA, Tangen CM, Ungerleider JS, et al. Fluorouracil plus levamisole as effective adjuvant therapy after resection of stage III colon carcinoma: a final report. Ann 
Intern Med. 1995;122(5):321-326.

74. Seeber A, Gastl G. Targeted Therapy of Colorectal Cancer. Oncol Res Treat. 2016;39(12):796-802.

75. Venook AP, Niedzwiecki D, Innocenti F, et al. Impact of primary tumor location on overall survival and progression-free survival in patients with metastatic colorectal cancer: analysis of CALGB/SWOG 80405 (Alliance). J Clin Oncol. 2016;34:3504.

76. Brule SY, Jonker DJ, Karapetis CS, O'Callaghan CJ, Moore MJ, Wong R, Tebbutt NC, et al. Location of colon cancer (right-sided versus left-sided) as a prognostic factor and a predictor of benefit from cetuximab in NCIC CO.17. Eur J Cancer. 2015;51(11):1405-1414.

77. Tejpar S, Stintzing S, Ciardiello F, Tabernero J, Van Cutsem E, Beier F, Esser R, et al. Prognostic and predictive relevance of primary tumor location in patients with RAS wild-type metastatic colorectal cancer: retrospective analyses of the CRYSTAL and FIRE-3 trials. JAMA Oncol. 2017;3(2):194-201.

78. Boeckx N, Koukakis R, Op de Beeck K, Rolfo C, Van Camp G, Siena S, Tabernero J, et al. Primary tumor sidedness has an impact on prognosis and treatment outcome in metastatic colorectal cancer: results from two randomized first-line panitumumab studies. Ann Oncol. 2017;28(8):1862-1868.

79. Salem ME, Weinberg BA, Xiu J, El-Deiry WS, Hwang JJ, Gatalica Z, Philip PA, et al. Comparative molecular analyses of left-sided colon, right-sided colon, and rectal cancers. Oncotarget. 2017;8(49):86356-86368.

80. Aljehani MA, Morgan JW, Guthrie LA, Jabo B, Ramadan M, Bahjri K, Lum SS, et al. Association of primary tumor site with mortality in patients receiving bevacizumab and cetuximab for metastatic colorectal cancer. JAMA Surg. 2018;153(1):60-67.

81. Kloor M, von Knebel Doeberitz M. The 1mmune biology of microsatellite-unstable cancer. Trends Cancer. 2016;2(3):121-133.

82. Pardoll DM. The blockade of immune checkpoints in cancer immunotherapy. Nat Rev Cancer. 2012;12(4):252264.

83. Gatalica Z, Vranic S, Xiu J, Swensen J, Reddy S. High microsatellite instability (MSI-H) colorectal carcinoma: a brief review of predictive biomarkers in the era of personalized medicine. Fam Cancer. 2016;15(3):405-412.

84. Jenkins RW, Barbie DA, Flaherty KT. Mechanisms of resistance to immune checkpoint inhibitors. Br J Cancer. 2018;118(1):9-16.

85. Topalian SL, Taube JM, Anders RA, Pardoll DM. Mechanism-driven biomarkers to guide immune checkpoint blockade in cancer therapy. Nat Rev Cancer. 2016;16(5):275-287.

86. Topalian SL, Drake CG, Pardoll DM. Immune checkpoint blockade: a common denominator approach to cancer therapy. Cancer Cell. 2015;27(4):450-461.

87. Van Allen EM, Miao D, Schilling B, Shukla SA, Blank C, Zimmer L, Sucker A, et al. Genomic correlates of response to CTLA-4 blockade in metastatic melanoma. Science. 2015;350(6257):207-211.

88. Brahmer JR, Tykodi SS, Chow LQ, Hwu WJ, Topa- lian SL, Hwu P, Drake CG, et al. Safety and activity of anti-PD-L1 antibody in patients with advanced cancer. N Engl J Med. 2012;366(26):2455-2465.

89. Chung KY, Gore I, Fong L, Venook A, Beck SB, Dorazio P, Criscitiello PJ, et al. Phase II study of the anti-cytotoxic T-lymphocyte-associated antigen 4 monoclonal antibody, tremelimumab, in patients with refractory metastatic colorectal cancer. J Clin Oncol. 2010;28(21):3485-3490.

90. Le DT, Uram JN, Wang H, Bartlett BR, Kemberling $\mathrm{H}$, Eyring AD, Skora AD, et al. PD-1 Blockade in Tumors with Mismatch-Repair Deficiency. N Engl J Med. 2015;372(26):2509-2520.

91. Diaz L, Marabelle A, Delord J et al. Pembrolizumab therapy for microsatellite instability high (MSI-H) colorectal cancer (CRC) and non-CRC. J Clin Oncol. 2017;35:3071.

92. Kang SP, Gergich K, Lubiniecki GM, de Alwis DP, Chen C, Tice MAB, Rubin EH. Pembrolizumab KEYNOTE-001: an adaptive study leading to accelerated approval for two indications and a companion diagnostic. Ann Oncol. 2017;28(6):1388-1398.

93. Overman MJ, McDermott R, Leach JL, Lonardi S, Lenz HJ, Morse MA, Desai J, et al. Nivolumab in patients with metastatic DNA mismatch repair-deficient or microsatellite instability-high colorectal cancer (CheckMate 142): an open-label, multicentre, phase 2 study. Lancet Oncol. 2017;18(9):1182-1191.

94. Andre T, Lonardi S, Wong KYM, et al. Combiantion of nivolumab (nivo)+ ipilumumab (ipi) in the treatment of patients(pts) with deficient DNA mismatch repair (dMMR)/high microsatellite instability (MSI-H) metastatic colorectal cancer (mCRC): Checkmate 142 study. Proc Am Soc Clin Oncol. 2017;35:353.

95. Jacob BJ, Moineddin R, Sutradhar R, Baxter NN, Urbach DR. Effect of colonoscopy on colorectal cancer incidence and mortality: an instrumental variable analysis. Gastrointest Endosc. 2012;76(2):355-364 e351.

96. Bishehsari F, Mahdavinia M, Vacca M, Malekzadeh R, Mariani-Costantini R. Epidemiological transition of colorectal cancer in developing countries: environmental factors, molecular pathways, and opportunities for prevention. World J Gastroenterol. 2014;20(20):6055-6072.

97. Hansen IO, Jess P. Possible better long-term survival in left versus right-sided colon cancer - a systematic review. Dan Med J. 2012;59(6):A4444.

98. Nitsche U, Stogbauer F, Spath C, Haller B, Wilhelm D, Friess H, Bader FG. Right sided colon cancer as a distinct histopathological subtype with reduced prognosis. Dig Surg. 2016;33(2):157-163.

99. Brenner H, Hoffmeister M, Arndt V, Stegmaier C, Altenhofen L, Haug U. Protection from right- and left-sided colorectal neoplasms after colonoscopy: populationbased study. J Natl Cancer Inst. 2010;102(2):89-95.

100. Schrag D, Rifas-Shiman S, Saltz L, Bach PB, Begg CB. Adjuvant chemotherapy use for Medicare beneficiaries with stage II colon cancer. J Clin Oncol. 2002;20(19):3999-4005.

101. Gill S, Loprinzi CL, Sargent DJ, Thome SD, Alberts SR, Haller DG, Benedetti J, et al. Pooled analysis of fluorouracil-based adjuvant therapy for stage II and III colon 
cancer: who benefits and by how much? J Clin Oncol. 2004;22(10):1797-1806.

102. Wang F, Bai L, Liu TS, Yu YY, He MM, Liu KY, Luo HY, et al. Right-sided colon cancer and left-sided colorectal cancers respond differently to cetuximab. Chin J Cancer. 2015;34(9):384-393.

103. Sclafani F. PD-1 inhibition in metastatic dMMR/MSI-H colon cancer. Lancet Oncol. 2017;18:9. 